\title{
Purpose and procedure
}

The general purpose of Evidence-Based Mental Health is to select from the health-related literature* those articles reporting important advances in treatment, diagnosis, aetiology, prognosis, continuing education, economic evaluation, and qualitative research in mental health. We select and summarise the highest quality original and review articles. Experts in the field comment on the clinical relevance and context of each study.

Our target audience includes psychiatrists, psychologists, nurses, social workers, occupational therapists, pharmacists, and other professionals whose work may be enhanced by up to date research. Evidence-Based Mental Health is multidisciplinary. It covers studies of adults, children, older adults, people who have developed psychiatric or psychological problems as a result of trauma, and people with learning disabilities, head injuries, drug and alcohol problems, and personality disorders.

Relevant articles which meet these criteria are summarised using a structured abstract. Articles are reviewed by experts in the field who provide commentaries describing the context of the article, methodological problems that may affect interpretation, and recommendations for clinical application.

The Royal College of Psychiatrists, the British Psychological Society and the BMJ Publishing Group publish Evidence-Based Mental Health.

\section{CRITERIA FOR SELECTION AND REVIEW OF ARTICLES}

Articles are considered for inclusion in Evidence-Based Mental Health if they are:

- original or review articles

- in English

- about humans

- about topics that are important to clinical practice in the field of mental health

- use analysis techniques consistent with the study design.

\section{Studies of prevention, treatment, quality improvement, and continuing education must also:}

- randomly allocate participants to comparison groups

- measure an outcome of known or probable clinical importance.

\section{Studies of causation (aetiology) must also:}

- collect data prospectively if possible

- identify a comparison group(s) for the outcome of interest.

\section{Studies of diagnosis must also:}

- include a spectrum of participants, some, but not all of whom have the disorder of interest

- include a diagnostic (gold) standard

- ensure each participant receives both the new test and some form of the diagnostic standard.

\section{Studies of prognosis must also:}

- include an inception cohort of participants (first onset or assembled at a uniform point in the development of the disease), all initially free of the outcome of interest.

\section{Studies of prevalence must also:}

- include a valid and repeatable definition of the disease or disorder

- employ adequate sampling methods.

\section{Studies of the cost-effectiveness of interventions must also:}

- compare alternative diagnostic or therapeutic services or quality improvement strategies

- compare activities on the basis of the outcomes produced (effectiveness) and resources consumed (costs)

- include data from real (not hypothetical) participants from studies which meet the quality criteria for other articles described above

- present results in terms of the incremental or additional costs and outcomes of one intervention over another

\section{Review articles}

In review articles, at least one article included in the review must meet the quality criteria for treatment, diagnosis, prognosis, causation, and cost effectiveness studies described above. Review articles must also:

- clearly state the clinical topic

- describe sources and methods

- explicitly state inclusion and exclusion criteria for selecting articles.

\section{Qualitative studies must meet the following criteria:}

- the content must relate to how people feel or experience situations that relate to mental health care

- data collection methods must be appropriate for qualitative studies. (For example, unstructured interviews, semi-structured interviews, participant observation of people in natural settings, focus groups, review of documents or text).

* Journals currently reviewed

Acta Psychiatrica Scandinavica

Addiction

Age and Ageing

American Journal of Gastroenterology

American Journal of Medicine

American Journal of Psychiatry

Annals of Emergency Medicine

Annals of Internal Medicine

Annals of Surgery

ANS Advances in Nursing Sciences

Applied Nursing Research

Archives of Disease in Childhood Neonatal and Fetal

Archives of General Psychiatry

Archives of Internal Medicine

Archives of Neurology

Archives of Pediatric and Adolescent Medicine

Arthritis and Rheumatism

Australian and New Zealand Journal of Psychiatry

Behaviour Research and Therapy

Birth

BJOG

BMC Psychiatry

BMJ

British Journal of Clinical Psychology 
British Journal of General Practice

British Journal of Psychiatry

British Journal of Surgery

Canadian Journal of Gastroenterology

Canadian Journal of Infection Control

Canadian Journal of Psychiatry

Canadian Respiratory Journal

Circulation

CMAJ

Cochrane Database of Systematic Review

Critical Care Medicine

Developmental Medicine and Child Neurology

Diabetes Care

Diabetic Medicine

Eur Child Adolesc Psychiatry

Evid Rep Technol Assess (Full Rep)

Gastroenterology

Gut

Health Education and Behavior

Health Psychology

Health technology assessment reports

Heart

Journal of Nursing Scholarship

International Journal of Geriatric Psychiatry

JAMA

Journal of Abnormal Child Psychology

Journal of Advanced Nursing

Journal of Affective Disorders

Journal of Anxiety Disorders

Journal of Child Psychology and Psychiatry and Allied

Disciplines

Journal of Clinical Epidemiology

Journal of Clinical Nursing

Journal of Clinical Psychiatry
Journal of Clinical Psychopharmacology

Journal of Consulting and Clinical Psychology

Journal of Family Practice

Journal of Infectious Disease

Journal of Manipulative and Physical Therapy

Journal of Neurology, Neurosurgery, and Psychiatry

Journal of Pediatrics

Journal of Psychosomatic Research

Journal of the American Academy of Child and Adolescent

Psychiatry

Journal of the American Geriatrics Society

Journal of Vascular Surgery

Lancet

Medical Care

Medical Journal of Australia

Medicine

Midwifery

Molecular Psychiatry

Neurology

New England Journal of Medicine

Pain

Pediatrics

PLOS Medicine

Psychiatric Services

Psychological Medicine

Psychosomatic Medicine

Qualitative Health Research

Schizophrenia Bulletin

Schizophrenia Research

Social Science and Medicine

Spine

Stroke

Thorax

Western Journal of Nursing Research. 